\title{
Incorporating Community Engagement Language into Promotion and Tenure Policies: One University's Journey
}

\author{
Lynn E. Pelco and Catherine Howard
}

\begin{abstract}
This case study describes the campus context and process for successfully including community engagement language into promotion and tenure policies at Virginia Commonwealth University, a high research, urban public university. The paper also describes barriers our campus faced during the promotion and tenure policy revision process, especially myths that emerged surrounding communityengaged work in the academy. We describe key supports that facilitated a successful process, including the important champions who played roles on our campus.
\end{abstract}

\section{Introduction}

Colleges and universities across the country are recognizing the need to create campus climates that support faculty for undertaking community-engaged teaching, scholarship, and service. These activities address pressing societal needs, and a growing number of faculty members are already engaging in them. For example, a 2010-2011 faculty survey from the Higher Education Research Institute at the University of California, Los Angeles showed that 42.5 percent of faculty respondents had "collaborated with the local community in research/teaching" during the past two years (Hurtado, et al. 2012).

One important strategy campuses are using to create cultures that validate community-engaged research, teaching, and service is to shift the institution's professional reward structure so that it explicitly recognizes this work. Higher education promotion and tenure policies also serve the important role of socializing faculty members to the values of the institution, and in this way they reinforce institutional missions and strategic plans that include community or civic engagement language. O'Meara, Eatman, and Petersen (2015) state, “...the promotion and tenure process reflects institutional values, aspirations, privileges, and power structures. Virtually every campus enacting serious change with regard to curricula, technology, globalization, learning, or retention must also face the implications for promotion and tenure."

This institutional case study examines one university's experience in revising its promotion and tenure policies to include community engaged forms of teaching, scholarship and service. Our experiences through this process are in many ways unique to our own institution; however, we believe many of our experiences represent common steps through which other campuses have or will travel as they address the growing need to foster innovative, community-engaged approaches to faculty work within the academy.

\section{Origins and context of community engagement at VCU}

Virginia Commonwealth University (VCU) has had a long tradition of urban community engagement. In 1968, the Virginia governor signed into law the merger of two historic higher education institutions, the Medical College of Virginia (MCV) and the Richmond Professional Institute (RPI). Both institutions were born out of critical needs in the community and were located in the center of the capital city of Richmond. This new university had the unique focus of filling the gaps of unmet higher education needs and of being urban-oriented with a concentration on meeting the needs of an urban population (Bonis, Koste, \& Lyons, 2006). As noted in the Wayne Commission report, "It has become increasing apparent

Copyright (C) 2016 Metropolitan Universities Vol. 27 No. 2 (Summer 2016), 87-98, DOI: 10.18060/21129 
that the conditions prevailing in our urban centers present many of our most critical national, state and local problems... Rarely has so challenging an opportunity to combine the free pursuit of knowledge in its own right with the ready availability of that knowledge for the enlightenment and enrichment of the larger community of which it is a part been presented to an institution of higher education." (Report of the Commission to Plan for the Establishment of a Proposed State-Supported University in the Richmond Metropolitan Area, 1967)

Both VCU and Richmond have changed dramatically over the ensuing 50 years. For example, between 1968 and 2015, VCU's student enrollment increased from 10,000 to 32,000 students, and the campuses grew to occupy 144 acres in the center of Richmond. During that same period, the population of the city of Richmond dropped from approximately 250,000 to 214,000; and like many other U.S. urban centers during this time period, Richmond's residents experienced higher rates of poverty and unemployment than did residents from the suburban communities that surrounded the city. Consequently, the need for VCU to expand its engagement with its neighboring communities has grown across time, and the university has worked to meet that need.

For example, by 1978 VCU had formalized support for its community engagement activities through the establishment of the Division of Continuing Studies and Public Service, which in 2006 was renamed the Division of Community Engagement (DCE). The DCE is administered from the Provost's Office and is now led by a vice provost for community engagement who reports directly to the provost. The Division provides support and coordination for community-engaged teaching, research and outreach activities across all academic units on both campuses and currently employs more than 20 full time staff members. In 2006 and 2015 the Division led VCU's successful applications to gain recognition from The Carnegie Foundation for the Advancement of Teaching as a community engaged institution.

Commitment to community engagement is also evident in the university's strategic plans across time. The most recent strategic plan, Quest for Distinction, was adopted in May 2011 and includes specific language and assessment metrics regarding the university's goal to become a national model for community engagement and regional impact.

\section{Developing campus-wide community engagement definitions}

Annually, the DCE co-sponsors a university-wide Council for Community Engagement that engages 40 representatives from both academic and administrative units. Council members are responsible for educating colleagues in their units about important university-level community engagement initiatives, distributing internal grant funding for interdisciplinary community-engagement initiatives, and recognizing outstanding community-university partnerships.

During the 2010-2011 academic year, Council members began to call for VCU to established shared definitions of important community engagement terms. It was clear to Council members that faculty and administrators within and across units interpreted community engagement terms such as community, partnership, and community-engaged service in different ways. These different interpretations inevitably led to miscommunications and confusion about community engagement activities both amongst and across campus groups.

As a first step, Council members requested that the DCE investigate community engagement definitions being used by peer institutions. During the summer of 2011, the vice provost for community engagement supervised a graduate student intern who conducted this research. The results were shared with Council members in the fall of 2011 and showed that peer institutions used a wide variety of definitions for key community engagement terms. The consensus of the Council that autumn was to craft and approve a VCU list of community engagement terms and definitions by adapting definitions used by peer 
institutions and national organizations (Carnegie Foundation for the Advancement of Teaching, 2011; Clinical and Translational Science Awards Consortium's Community Engagement Key Function Committee, 2011; Driscoll \& Sandmann 2011; Glassick, Huber, \& Maeroff, 1997; Harter, HamelLambert, \& Millesen, 2011; Lynton, 1995; Saltmarsh, 2010; The University of Kansas Beach Center on Disability, 2012; U.S. Department of Health and Human Services Office of Behavioral and Social Science Research, 2011). Throughout the rest of the Fall 2011 semester, DCE staff members along with several Council leaders worked to create this list of VCU definitions for the following key community engagement terms: community, partnership, community outreach, community engagement, communityengaged scholarship, community engaged-service, community-engaged teaching/learning, and community-engaged research. Drafts of the definitions were shared with the entire Council membership via online repositories (e.g., Blackboard) and all Council members were invited to edit and provide feedback.

By February 2012 the Council for Community Engagement members had approved by consensus the list of terms and definitions. At that same time, as we will describe below, the vice provost for community engagement hired an external expert consultant to help campus leaders and members of the new Ad Hoc Committee for the Revision of Promotion and Tenure Policies consider ways in which the university's community engagement mission could be articulated in the university's revised promotion and tenure policies. In concert with this work, the consultant provided feedback on the community engagement definitions, which were then presented to the Provost who forwarded them to the President's Cabinet for their approval. The terms were approved in August 2012 and were added to the institutional data glossary maintained by the Office of Planning and Decision Support. The approved definitions (shown in Table 1) were posted on the university's website.

Table 1

VCU Community Engagement Terms and Definitions

Community

Partnership

Community Outreach

Community

Engagement
A group of people external to the campus who are affiliated by geographic proximity, special interest, similar situation or shared values. Communities may share characteristics such as age, ethnicity, gender, or sexual orientation.

Sustained collaboration between institutions of higher education and communities for the mutually beneficial exchange, exploration, and application of knowledge, information, and resources. Examples are research, capacity building, or economic development.

The application and provision of institutional resources, knowledge or services that directly benefits the community. Examples include music concerts, athletic events, student volunteers, public lectures, or health fairs.

The collaboration between institutions of higher education and their larger communities for the mutually beneficial exchange of knowledge and resources in the context of partnership and reciprocity. It can involve partnerships and coalitions that help mobilize resources and influence systems and serve as catalysts for initiating and/or changing policies, programs, and practices. 


\section{Community- Engaged Scholarship}
Community- Engaged Service

Community- Engaged Teaching/ Learning

Community- Engaged Research
The creation and dissemination of knowledge and creative expression in furtherance of the mission and goals of the university and in collaboration with the community. Community-engaged scholarship (CES) addresses community needs through research, teaching and service in a mutually beneficial partnership. The quality and impact of CES are determined by academic peers and community partners.

The application of one's professional expertise that addresses a communityidentified need and supports the goals and mission of the university and the community. Community-engaged service may entail the delivery of expertise, resources and services to the community.

A pedagogical approach that connects students and faculty with activities that address community-identified needs through mutually beneficial partnerships that deepen students' academic and civic learning. Examples are service-learning courses or service-learning clinical praticums.

A collaborative process between the researcher and community partner that creates and disseminates knowledge and creative expression with the goal of contributing to the discipline and strengthening the wellbeing of the community. Community-engaged research (CER) identifies the assets of all stakeholders and incorporates them in the design and conduct of the different phases of the research process.

\section{Revising promotion and tenure policies to include community engagement language}

In the fall of 2011, the university president charged a 19-member Ad Hoc Committee to review and revise the promotion and tenure policies of the university. This Ad Hoc Committee for the Revision of Promotion and Tenure Policies convened for the first time in November 2011. The provost instructed the committee to insure that the revised policy clearly aligned with the university's new strategic plan, Quest for Distinction. The provost also required that the general criteria for promotion and tenure include community engagement language. To meet this requirement, the committee constructed a matrix that enabled tracking of the developing policy revision along the major themes of the university's strategic plan. During the next three months, the Ad Hoc Committee worked in subcommittees to collect information that would guide their work. These committees were the Peer Institution Review Subcommittee, the Literature Review Subcommittee, and the VCU School-Level Promotion and Tenure Policy Review Subcommittee. Each subcommittee utilized the matrix to map information it collected with the major themes of Quest for Distinction. Because community engagement existed as a major theme of Quest for Distinction, this matrix approach insured that the Ad Hoc Committee brought forward information related to community engagement language in the promotion and tenure policy revision.

In September 2011, the vice provost for community engagement hired an external expert consultant to work with key campus stakeholders around the topics of community engagement in the academy and community-engaged scholarship. The consultant met on campus with deans to help them understand the nature and role of community-engaged scholarship within their disciplines. During the fall semester, the consultant also met with members of the Council for Community Engagement and with the staff from the university's Center for Clinical and Translational Research. Finally, the consultant attended the fourth meeting of the Ad Hoc Committee, which was convened in February 2012, to facilitate a discussion about community engagement and community-engaged scholarship. 
The March 2012 meeting of the Ad Hoc Committee included a large group discussion of the ideas shared by the expert consultant the previous month. A number of key questions arose from the group, and these are described in the Barriers and Myths section below. The Ad Hoc Committee co-chairs sought answers to the committee members' questions by shuttling between the Ad Hoc Committee and various campus community engagement experts, including the vice provost for community engagement, the external expert consultant, and members of the Council for Community Engagement. Over the next few months, it became clear to the Ad Hoc Committee members that the community engagement definitions developed by the Council for Community Engagement during the Fall 2011 semester should be utilized in the promotion and tenure policy revision. Additionally, the Ad Hoc Committee members came to the consensus that language related to community engagement would be incorporated into each of the three general criteria - scholarship, teaching, and service. Specifically, the revised general criteria for promotion and tenure explicitly included community-engaged scholarship, community-engaged teaching, and community-engaged service as acceptable approaches to the work. The exact language included in the revised policy is shown in Table 2 .

\section{Table 2}

VCU Promotion and Tenure Policies General Criteria and Criteria Definitions for Tenured, Tenureeligible, and Term (non-tenure) Faculty Members

In order to ensure distinction in learning, research, scholarly pursuits and creative expression, and service, the following criteria shall apply in the evaluation of all tenured and tenure-eligible faculty members for promotion and tenure. For faculty members holding term (non-tenure) faculty appointments, the criteria shall be applied in the evaluation for promotion as appropriate to the individual faculty member's special mix of duties. All faculty members' work plans are developed in accordance with the Faculty Roles and Rewards policy. Faculty members holding administrative positions must meet the guidelines of their own academic unit. General criteria include:

General Criteria 1: Appropriate credentials and experience.

General Criteria 2: Demonstrated continuing scholarship and professional growth. Faculty members should be continuously engaged in productive and creative scholarly activity in areas relevant to the goals and mission of their academic unit. They should make a substantive contribution to the body of knowledge in their discipline that reflects high standards of quality in creativity, scholarship and professional competence. They should demonstrate leadership and professional competence in independent scholarship and/or collaborative research that leads to the creation of new knowledge or creative expression. Scholarship can be in the form of research and discovery scholarship, the scholarship of teaching and learning, or community-engaged research. Research and discovery scholarship breaks new ground in the discipline and answers significant questions in the discipline. Scholarship of teaching and learning includes applied research regarding various pedagogies, student learning, and assessment practices; development and dissemination of materials for use in teaching beyond one's own classroom. Community-engaged research is a collaborative process between the researcher and community partner at all stages of the research process. Examples are community-based participatory and action research.

General Criteria 3: Demonstrated quality in teaching. Teaching shall be evaluated based primarily upon the impact of the faculty member's teaching in programs relevant to the mission of their academic unit. Faculty members must demonstrate mastery of their subject matter and at communicating this understanding to student learners; most fundamentally, faculty members should demonstrate that their 
students learn. There should be evidence of the candidate's sustained commitment to classroom instruction, to inclusion of advising and availability to students as a component of teaching, to sustained effectiveness as a contributor to the intellectual development of students through devices such as course design, course material, curriculum development, and attention to other mechanisms of enhancing student learning. Mentoring, and other forms of beneficial interactions between the candidate and learners, may be given appropriate weight as a part of the teaching criteria as determined by the academic unit. Demonstrated quality of teaching may include community-engaged teaching that connects students and faculty members with activities that address community-identified needs through mutually beneficial partnerships that deepen students' academic and civic learning. Examples are service-learning courses or service-learning clinical practicums.

General Criteria 4: Demonstrated performance in service. Faculty members are expected to give of their time and expertise for the betterment of their department, school and university, their profession and/or the broader community. Service includes engaging in the application of learning and discovery to improve the human condition and support the public good at home and abroad. Demonstrated performance in service may include community-engaged service, which is the application of one's professional expertise to address a community-identified need and to support the goals and mission of the university and the community partner.

Approved May 2013.

By May 2012, the Ad Hoc Committee had submitted its revised policy in a final report to the provost. During the Fall 2012 semester, four open discussion forums were held on the campus so that stakeholders could respond to the proposed revision. Additionally, public comments were collected via an online platform. The Ad Hoc Committee met once more in December 2012 to incorporate suggestions from these forums into the document. No significant changes to the community-engagement language were made as a result of the public comments. The university's Board of Visitors approved the new university promotion and tenure policy in May 2013.

Once the new university promotion and tenure policy was approved, each of the 12 VCU schools and its College of Humanities and Sciences set to work revising their own unit-level policy so that it aligned with the new university policy. During the 2013-2014 academic year, these academic units worked to update their policies and to have these reviewed and approved by the University Promotion and Tenure Policy Review Committee. This committee consists of tenured faculty members who represent each school and who are appointed by the university president for 3-year terms. The Committee was responsible for insuring that the proposed unit-level policies aligned with the new university-level policy. As of Fall 2015, 11 of the 13 units had completed this review process and had approved unit-level Promotion and Tenure policies in place, while two units continue to work with the University Promotion and Tenure Policy Review Committee on their revisions. Of the 11 approved policies, 10 include language related to community-engaged teaching and community-engaged scholarship, and all 11 included language related to community-engaged service. Copies of these discipline-specific policies are available from the authors.

\section{Key champions}

Throughout the process of developing university specific community engagement definitions and incorporating community engagement language into the revised promotion and tenure policies, several key champions immerged. These champions, through their expertise, political and social capital, were able to help shape the positive trajectory of the process. 
These champions included the university provost, who insisted that the revised policies explicitly reflect the institution's strategic plan, in part by incorporating community engagement language. The external consultant and the vice provost for community engagement played the important role of providing Ad Hoc Committee members with real-time expert community engagement information, particularly information that benchmarked national community engagement trends and provided comparisons to both peer and aspirational institutions. The co-chairs of the Ad Hoc Committee facilitated the successful inclusion of community-engagement language by diligently working to address committee members' concerns and questions through ongoing dialogue with campus community engagement experts. As a group, the Ad Hoc committee was itself an asset because it included several members who were openly supportive of community-engaged scholarship, teaching and service as well as members who were receptive to the idea of widening the promotion and tenure policy general criteria to include a variety of high-quality approaches. An important champion was the vice president for research, who openly supported the recognition of a variety of scholarship methods. The vice president publicly stated that the most important criteria for determining what types of scholarship are acceptable were the quality of the scholarship and not the methodology used. These public statements helped to quiet small pockets of opposition to community-engaged research that arose both in the Ad Hoc Committee and across the campus during open forums.

\section{Barriers and myths}

The promotion and tenure policy revision process uncovered a number of beliefs and myths about community engaged academic work that existed on our campus and that needed to be dispelled before the policies would be revised to include community engagement language. These beliefs included misunderstandings about the definition of community engagement, the requirements for communityengaged scholarship, and the ingredients of institutional preeminence.

Many of our campus stakeholders initially held the belief that community engagement is a type of faculty service (i.e., service that occurs within the community). Community engagement, they believed, is an important and valued form of faculty service that exists alongside the more traditional service types, such as campus service (e.g., college committee work) and professional service (e.g., professional organization leadership) and should, therefore, be 'credited' in the service category of the revised policies. Faculty members and administrators across disciplines held this belief, including individuals from the social sciences, arts and humanities, STEM disciplines, and from our medical campus. Even when the community engagement definitions included both teaching and research activities, these individuals saw community engagement work as primarily a service activity. We used primarily educational strategies to debunk this belief, especially explanations, and institutional peer/national trend data, from campus and national community engagement experts such as the vice provost for community engagement and the external expert consultant. At one point during this educational process, the Ad Hoc Committee entertained the idea that community engagement was unique enough to warrant its own fourth criteria category. Again, our community engagement experts were successful in lobbying against this idea in favor of a more integrated approach that wove community engagement language into the existing three general criteria categories - scholarship, teaching, and service.

A second set of myths that surfaced from the Ad Hoc Committee membership involved the nature of community-engaged scholarship in the revised policies. Members expressed concerns related to processes for assessing the quality of community-engaged scholarship and to the availability of funding streams to support this type of research. Our community engagement experts addressed both of these concerns by providing the committee with specific examples for both assessment and funding.

Several members of the Ad Hoc Committee from STEM disciplines and our medical campus were concerned that including community-engaged scholarship into the scholarship category meant (a) moving 
forward, every faculty member would be required to include at least some community-engaged scholarship products in their promotion and tenure dossiers and (b) all research projects would now be required to involve lay community members as co-researchers. These myths were somewhat easier to dispel than was the 'community engagement equals service' myth. Two strategies were used to successfully educate committee members and to assuage their concerns. First, the Ad Hoc Committee cochairs proposed including excerpted portions of the community engagement definitions directly into the revised promotion and tenure policies to clarify what the institution meant by terms such as communityengaged scholarship, community-engaged teaching, and community-engaged service. Second, the cochairs proposed language for the revised policies that made clear the acceptable and optional nature of community-engaged work within the three criteria. This language involved phrases such as "scholarship can be in the form of..." and "quality teaching may include community-engaged....". In these ways, the language of the policies made clear to readers that community-engaged approaches to scholarship, teaching, and service were acceptable, but not required routes to promotion or tenure.

A final myth that arose, but that did not block passage of a final promotion and tenure policy revision that included community engagement language, is what we call the 'local engagement negates preeminence' myth. On a few occasions through the revision process, a small number of stakeholders expressed the opinion that an emphasis on community engagement would detract from the institution's goal of national and international preeminence. We do not know how widespread this belief might be on our campus, but it is a myth we know must be addressed if our campus is to truly embrace a culture of community engagement. The idea that faculty members who teach, conduct research, or engage in service within and with local communities are detracting from their university's goal to achieve national and international preeminence is an insidious and dangerous one. In a globalized and knowledge-based economy, the idea that working to address complex local problems is parochial may seem, on its surface, to have some merit. However, collaborative teams of university faculty researchers, students, and community members working on complex local problems hold the keys to unlocking solutions with worldwide applications. Additionally, technology now enables these local community-university teams to work collaboratively with parallel community-university teams from around the world, making the local truly global. We believe that only high-quality community-engaged work that demonstrates impact will finally extinguish support for the 'local engagement negates preeminence' myth on our campus and at other institutions of higher education around the world.

\section{Future challenges}

Our institution has successfully completed the process of including community-engagement language in its university- and school-level promotion and tenure policies. For these policies to truly influence campus culture, we must develop and implement a continuum of supports. O'Meara and her colleagues (2015) outline many of the strategies we must now develop at our institution to assist our faculty members, department chairs and deans, and the members of our promotion and tenure review committees in implementing these policies and supporting community-engaged faculty work.

First, we must continue to educate all members of our campus community about how communityengaged academic work differs from traditional research, teaching and service models; and we must explicitly describe why community-engaged faculty work is valued on our campus. Second, our university will need to develop criteria for evaluating community-engaged scholarship, communityengaged teaching, and community-engaged service; and these criteria will need to be applicable or adaptable across disciplines. We will need to provide both faculty members and administrators with examples of ways to document and evaluate high quality community-engaged academic work. While we recognize the importance of providing these types of supports for community-engaged scholarship, we want to emphasize that it is also critical to develop and implement similar supports for defining, documenting, and evaluating high-quality community-engaged teaching and community-engaged service. 
Regularly scheduled information sessions and professional development workshops targeted for specific campus stakeholder groups (e.g., department chairs, deans, promotion and tenure review committee members) can be effective formats for communicating the critical conceptual framework of communityengaged academic work. Open access online toolkits are also useful resources to support the work of academic administrators and faculty members as these can provide specific definitions, procedural guidelines, case examples, and contact information for receiving assistance from campus communityengagement experts.

When evaluating and rewarding faculty work, it will also be important for universities - including Virginia Commonwealth University - to increase the value of local impact so that it is afforded the same credibility in promotion and tenure reviews as national and international impact. O'Meara and her colleagues (2015) emphasize that it is "important for policy guidelines to articulate the value of local partnership development and to make it clear that local impact is as important as international impactand at all ranks. Because funding sources are often considered in research-focused institutions and in STEM fields, it is also helpful to signal acceptance of various kinds of funding sources as evidence of impact. Otherwise, faculty members may be disadvantaged for attracting practice-oriented foundation grants, for example, rather than federal research funding." We agree, and believe we will need to address this issue of local impact (e.g., the community-engagement negates preeminence myth) on our campuses in the future. 


\section{Conclusions}

The process of incorporating community-engagement language into the revised promotion and tenure policies at Virginia Commonwealth University involved multifaceted supports and occurred incrementally over decades. The process was successful, in part, because Virginia Commonwealth University, as an institution, had established a long history of substantive community-engagement and had already incorporated community-engagement as a central mission in its strategic plan and administrative infrastructure. High-quality community-engaged faculty work was already visible on our campus and, therefore, recognized by members of the Ad Hoc Committee for the Revision of Promotion and Tenure Policies. High-level campus administrators, especially the provost and the vice president for research, were outspoken supporters, and this fact also positively impacted the process. Finally, the vice provost for community engagement and the university's Council for Community Engagement spearheaded a well-timed strategy for developing university-wide community-engagement definitions and for hosting an external expert consultant who provided further supports for our successful promotion and tenure policy revision.

We recommend to other institutions working for the inclusion of community-engaged language in their promotion and tenure policy revisions that they assess how many of these types of supports they have or could put into place prior to the launch of the revision process. Our experience has taught us that each of these supports played a critically important role in our success story. We urge other institutions to recognize promotion and tenure revision as just one step along the road to developing a campus climate that supports faculty for undertaking community-engaged teaching, scholarship, and service rather than as the successful end point. The impact of community-engaged language in an institution's faculty reward structure ultimately depends on the quality and quantity of supports that institution provides to its members for deeply embracing that language. 


\section{References}

Agency for Toxic Substances \& Disease Registry. (2011). Principles of community engagement. Retrieved from http://www.atsdr.cdc.gov/communityengagement/pdf/PCE_Report_508_Final.pdf.

Bonis, R., Koste, J., \& Lyons, C. (2006). Virginia Commonwealth University: The campus history series. Charleston: Arcadia Publishing.

Carnegie Foundation. (2011). Classification description: Community engagement elective classification. Retrieved from http://classifications.carnegiefoundation.org/descriptions/community_engagement.php.

Commonwealth of Virginia. (1967). Report of the Commission to plan for the establishment of a proposed state-supported university in the Richmond Metropolitan Area. Richmond, VA: Commonwealth of Virginia Department of Purchases and Supply.

Glassick, C., Huber, M. \& Maeroff, G. (1997). Scholarship assessed: Evaluation of the professoriate. San Francisco, CA: Jossey Bass.

Harter, L., Hamel-Lamber, J. \& Milesen, J. (2010). Participatory Partnerships for Social Action and Research. Dubuque, IA: Kendall Hunt Press.

Hurtado, S., Eagan, K., Pryor, John H., Whang, H., \& Tran, S. (2012). Undergraduate Teaching Faculty: The 2010-2011 HERI Faculty Survey. Los Angeles: Higher Education Research Institute, University of California, Los Angeles.

Lynton, E. (1995). Making the case for professional service. Washington, DC: Stylus Publishing, LLC.

O’Meara, K. A., Eatman, T., \& Petersen, S. (2015). Advancing engaged scholarship in promotion and tenure: A roadmap and call for reform. Liberal Education 101 (3). Retrieved from http://www.aacu.org/liberaleducation/2015/summer/o\%27meara.

Saltmarsh, John. (2010). Engaged pedagogy. In H. Fitzgerald, C. Burack, \& S. Seifer (Eds.) Handbook of engaged scholarship: Contemporary landscapes for future directions 2010, pp. 331-352. East Lansing: Michigan State University Press.

Saltmarsh, J., Warren, M. R., Krueger-Henney, P., Rivera, L., Fleming, R. K., Friedman, D. H., \& Uriarte, M. (2015). Creating an academic culture that supports community-engaged scholarship. Diversity and Democracy 18 (1). Retrieved from https://www.aacu.org/diversitydemocracy/2015/winter/saltmarsh.

Scholarship of Engagement. (2011). Evaluation criteria for the scholarship of engagement. Retrieved from http://www.scholarshipofengagement.org/evaluation_criteria.html.

The University of Kansas Beach Center on Disability. (2011). Participatory action research. Retrieved from

http://obssr.od.nih.gov/scentific_areas/methodology/community_based_participatory_research/index.aspx

U.S. Department of Health and Human Services Office of Behavioral and Social Science Research. 2011. Community-based participatory research. Retrieved from

http://obssr.od.nih.gov/scientific area/methodology/community based participatory research/index.as. 


\section{Author Information}

Dr. Lynn E. Pelco is the Associate Vice Provost for Community Engagement at Virginia Commonwealth University, where she is also the director of service-learning and affiliate professor in the School of Education. Her research and teaching interests include high-impact educational practices and university student development.

Lynn E. Pelco

Associate Vice Provost for Community Engagement

Virginia Commonwealth University

Division of Community Engagement

901 W. Franklin Street

P.O. Box 843062

Richmond, VA 23284-3062

Telephone: 804-827-8215

Email: lepelco@vcu.edu

Dr. Catherine Howard is the Vice Provost for Community Engagement at Virginia Commonwealth University and Associate Professor in the Department of Psychology. She co-chairs the VCU Council for Community Engagement and has focused on creating a culture of community engagement throughout the campus.

Catherine Howard

Vice Provost for Community Engagement

Virginia Commonwealth University

Division of Community Engagement

$901 \mathrm{~W}$. Franklin Street

P.O. Box 843062

Richmond, VA 23284-3062

Telephone: 804-828-8790

Email: choward@vcu.edu 